\title{
Thermomechanical Treatment of High-Shear Melt-Conditioned Twin-Roll Cast Strip of Recycled AA5754 Alloy
}

\author{
KAWTHER AL-HELAL ${ }^{1,},{ }^{1,2}$ ISAAC CHANG,${ }^{1}$ JAYESH B. PATEL,${ }^{1}$ \\ and ZHONGYUN FAN ${ }^{1}$ \\ 1.-BCAST, Brunel University, Uxbridge UB8 3PH, UK. 2.—e-mail: kawther.al-helal2@brunel.ac.uk
}

A continuous high-shear melt conditioning twin-roll casting process has been developed for production of recycled aluminum alloy strip with minimum casting defects. High-shear melt conditioning is applied to increase the impurities tolerance of recycled aluminum. The results of this study showed that solidification during twin-roll casting can be controlled by using intensive melt conditioning prior to casting, which can promote equiaxed growth with minimal defects and result in improved sheet quality. Melt-conditioned twinroll cast (MC-TRC) AA5754 alloy exhibited fine equiaxed grains and homogenized matrix structure while centerline segregation was eliminated. As-cast melt-conditioned twin-roll cast AA5754 strips showed clear grain recrystallization after thermomechanical treatment at $430^{\circ} \mathrm{C}$ for $30 \mathrm{~min}$, representing an improvement over conventional twin-roll casting. The MC-TRC strip showed $57.2 \%$ higher elongation and $4.1 \%$ higher ultimate tensile strength compared with the TRC strip after applying melt conditioning with thermomechanical treatment.

\section{INTRODUCTION}

High strength and good formability, weldability, and corrosion resistance are properties required of aluminum sheet for automotive applications; ${ }^{1}$ For example, 5000 series alloys containing $2-5 \% \mathrm{Mg}$, e.g., AA5754, possess high strength and excellent stretch-forming characteristics. For automotive applications, development of casting processes to produce low-cost aluminum alloy sheet is essential. Use of recycled aluminum alloys or development of an economical process is the best strategy to reduce the cost of producing aluminum alloy sheet. With the increasing use of recycled aluminum alloys, the great challenge for the aluminum industry is control of the inclusion content. During recycling, a certain amount of $\mathrm{Fe}$ and other elements will be mixed into the original aluminum alloys, degrading their mechanical properties. To achieve cost reduction and low environmental impact, it is therefore necessary to increase the $\mathrm{Fe}$ content tolerance of recycled aluminum alloys. Due to the low solubility of Fe in the solid phase of aluminum alloys, it tends to form various types of intermetallic phase particles by combination with other elements. ${ }^{2} \mathrm{Fe}$ intermetallic with platelet morphology such as $\mathrm{Al}_{13} \mathrm{Fe}_{4}$ is one of the undesirable Fe-rich phases, and is thought to be the most harmful phase. Because of its brittleness, it forms points of weak coherence and stress raisers, resulting in severe loss of ductility and strength in aluminum alloys. The size of the platelet phase increases with increase of the iron content or decrease of the cooling rate. ${ }^{3}$

To reduce the negative effect of $\mathrm{Fe}$ phases on aluminum alloys, many studies have been carried out to investigate the formation mechanism of Ferich intermetallics and their effect on mechanical properties. ${ }^{4}$ Rapid solidification of recycled aluminum alloy is the best method of improving the mechanical properties. The twin-roll casting process is an economic process that can accomplish rapid solidification to produce aluminum sheet from recycled aluminum alloy. ${ }^{5}$ Twin-roll casting is an established continuous process for direct production of alloy strip from the melt, as it combines casting and deformation into one step. ${ }^{6}$ Casting defects produced in the twin-roll cast (TRC) process can be categorized into surface defects such as bleeds and cracks, internal defects such as centerline 
segregation, and macroscopic buckling. ${ }^{1}$ Traditionally, TRC has been limited to relatively pure aluminum alloys, largely because of the tendency for more alloyed materials to stick to the caster rolls and/or develop microstructures with internal and surface defects that are unsuitable for further downstream processing such as forming.

In 2007, BCAST at Brunel University developed melt conditioning by advanced shear technology (MCAST), a process for conditioning liquid metal using a high-shear twin-screw mechanism at temperatures around the alloy liquidus. The MCAST process has been combined with the twin-roll casting (TRC) process to form an innovative technology, namely the melt-conditioned twin-roll casting (MC-TRC) process, for casting $\mathrm{Al}$ alloy and $\mathrm{Mg}$ alloy strips in a batchwise process. Recently, a continuous melt-conditioning twin-roll casting (MC-TRC) process was developed. In this process, a rotor-stator device was employed for intensive shearing of the melt and integrated with TRC. The rotor-stator device was found to be more efficient and practical to use in comparison with the twinscrew mechanism. Generally, the main advantages of melt conditioning include homogenization of the temperature and chemical composition close to the solidification front, improvement of chemical reactions within the melt, and fragmentation and dispersion of naturally occurring oxides, as well as an increase in their wettability. As a result, oxide particles can act as heterogeneous nucleation sites for grain refinement, overcoming the limitations of the conventional twin-roll casting process. ${ }^{7-10}$

For the first time, strips of AA5754 scrap analog and binary $\mathrm{Al}-\mathrm{Mg}$ alloys were successfully cast using MC-TRC processes developed in BCAST. ${ }^{8,10}$ Kumar et al. ${ }^{10}$ used a twin-screw mechanism in the batch MC-TRC process to cast AA5754 analog alloy. The results showed fine equiaxed grains and a uniform structure with the elimination of centerline segregation in comparison with TRC strips. Nilam et al. ${ }^{8}$ tested the rotor-stator technology in the continuous MC-TRC process and found that melt conditioning increased the limit of $\mathrm{Mg}$ content in $\mathrm{Al}-$ $\mathrm{Mg}$ alloy by up to $7 \%$ without severe segregation. This reduction in the centerline segregation can be attributed to the enhanced nucleation process due to the dispersed oxide particles.

Using rotor-stator HSMC for casting $\mathrm{Al}-3 \mathrm{Mg}$, Nilam et al. ${ }^{11}$ found that the MC-TRC strip after thermomechanical treatment showed $22 \%$ higher elongation with uniform plastic deformation in comparison with the TRC strip.
In this study, conventional twin-roll casting (TRC) and melt-conditioning twin-roll casting (MC-TRC) processes were carried out on recycled AA5754 aluminum alloy, followed by thermomechanical treatment. The impact of the microstructure of the conventional TRC and melt-conditioned MC-TRC strips on the mechanical properties after thermomechanical treatment was investigated.

\section{EXPERIMENTAL PROCEDURES}

\section{Equipment and Materials}

A horizontal small-scale version of the twin-roll caster was used in this study, consisting of two stainless-steel rolls with diameter of $318 \mathrm{~mm}$ and width of $350 \mathrm{~mm}$, opposed vertically to one another with the strip exiting horizontally. The rolls were internally water cooled, with each being driven independently by an electric motor and gearbox. The gap between the rolls was set manually, with maximum peripheral roll speed of around $15 \mathrm{~m} / \mathrm{min}$.

Experiments were carried out using a high-shear melt conditioning (HSMC) chamber and tundish/tip assembly made of N17 refractory board. The HSMC device consisted of a rotor and stator assembly made from a special material capable of working in molten aluminum. A detailed description and sketch of the high-shear melt conditioning twin-roll technology were reported in a previous publication. ${ }^{11}$ An electrically heated tilting furnace with $10 \mathrm{~kg}$ melt capacity was incorporated into the line for temperature control of the liquid metal and allows larger quantities of metal to be processed. Once the melt is poured into the chamber, the sheared material overflows into the tundish/tip assembly and into the roll bite.

AA5754 process scrap alloy with the composition shown in Table I, supplied by Primetals, Ltd., was used for the current study. Experiments were conducted first to optimize the TRC operating conditions such as the pouring temperature, casting speed, and setback for a range of roll gaps for both conventional TRC and MC-TRC; For example, the optimum operating conditions for a 2-mm roll gap were found to be setback of $35 \mathrm{~mm}$ and roll speed of $3.6 \mathrm{~m} / \mathrm{min}$. Based on trials using a simple tundish/ tip arrangement, it has been established that the optimum temperature of the melt in the tundish nozzle is around $660^{\circ} \mathrm{C}$ and the melt pouring temperature was $668^{\circ} \mathrm{C}$. In the case of MC-TRC experiments, the preheated mixer was inserted at the center of the feeding box which filled with the melt at $668^{\circ} \mathrm{C}$, and shearing started prior to adding the melt for the continuous casting process. The

Table I. As-received composition of AA5754 process scrap alloy

\begin{tabular}{llllllllll}
\hline Composition & $\frac{\mathbf{M g}}{3.54}$ & $\frac{\mathbf{M n}}{0.49}$ & $\frac{\mathbf{F e}}{0.23}$ & $\frac{\mathbf{S i}}{0.4}$ & $\frac{\mathbf{C r}}{0.018}$ & $\frac{\mathbf{Z n}}{0.010}$ & $\frac{\mathbf{T i}}{0.01}$ & $\frac{\mathbf{C u}}{0.017}$ & $\frac{\mathbf{A l}}{\text { Balance }}$ \\
\hline
\end{tabular}


melt conditioning was conducted at $3000 \mathrm{rpm}$. Strips of AA5754 alloy with width of $110 \mathrm{~mm}$ and gauge thickness of $3.2 \mathrm{~mm}$ were successfully produced from the conventional and MC-TRC processes.

\section{Thermomechanical Treatment and Mechanical Testing}

For thermomechanical treatment, samples from as-cast strips were taken towards the end to ensure that the process was as close to steady state as possible within the limits of the machine. The $3.2 \mathrm{~mm}$ gauge thickness as-cast strips were homogenized at $520^{\circ} \mathrm{C}$ for $8 \mathrm{~h}$ followed by air cooling to room temperature. Deformation by cold rolling was applied to reduce the thickness of the homogenized strips to $1.0 \mathrm{~mm}$. Residual stresses accumulated in the strips during the deformation process were relieved by annealing heat treatment at $430^{\circ} \mathrm{C}$ for $30 \mathrm{~min}$, followed by air cooling to room temperature. Rectangular tensile specimens were machined from as-cast, homogenized, and annealed strips from conventional and melt conditioning twin-roll casting. The dimensions of the tensile test specimen were based on ASTM B557 M-14, as shown in Fig. 1. Tensile tests were carried out on at least five samples from each of the longitudinal and transverse section for all processing conditions. An
Instron 5500 universal electromechanical testing system equipped with Bluehill software and $a \pm 50 \mathrm{kN}$ load cell was used for the mechanical tests. The strain rate was set to $1 \mathrm{~s}^{-1}$, and the tests were conducted at room temperature until failure.

\section{Characterization}

For metallography characterization, samples of longitudinal (RD) and transverse (TD) sections were mounted in Bakelite, ground, and polished with $0.04-\mu \mathrm{m}$ silica in water suspension. Anodization of polished samples was carried out at $20 \mathrm{~V}$ for $55 \mathrm{~s}$ in Barker's reagent to reveal the grain size and morphology. A Zeiss Axio-Vision optical microscope was used for microstructural analysis on the transverse and longitudinal cross-sections of the TRC and MC-TRC strips. The linear intercept method was implemented to measure the average grain size on polarized images.

\section{RESULTS AND DISCUSSION}

\section{Microstructure and Characterization of AA5754 Alloy}

Figures 2 and 3 show optical micrographs and the grain size distribution of as-cast AA5754 strip cast using the conventional TRC and MC-TRC process. Micrographs of as-cast TRC showed large dendritic

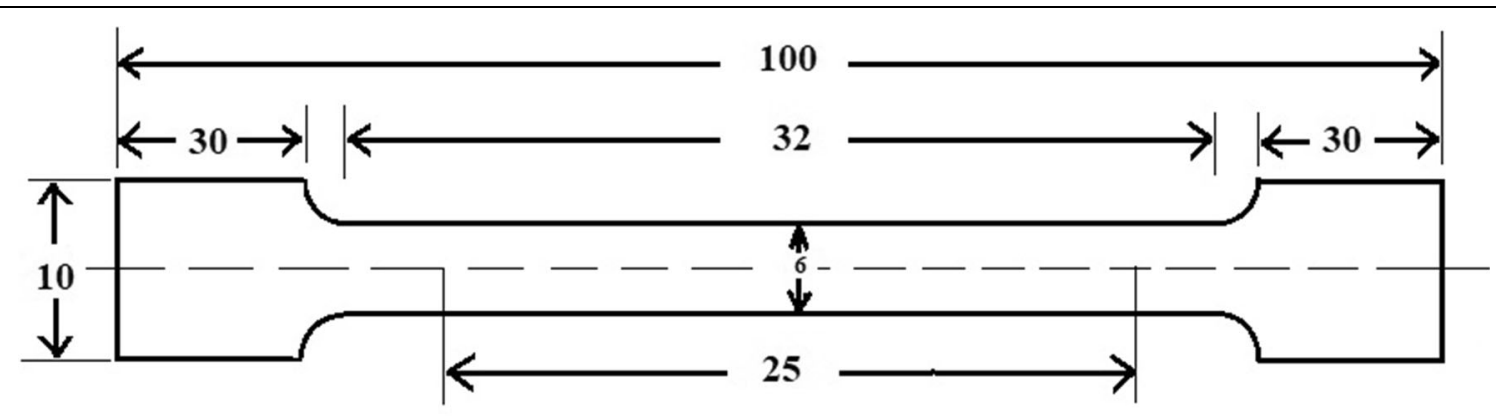

Fig. 1. Rectangular tensile test specimen according to ASTM B557 M-14 standard; all dimensions in mm. (Adapted from Ref. 12).
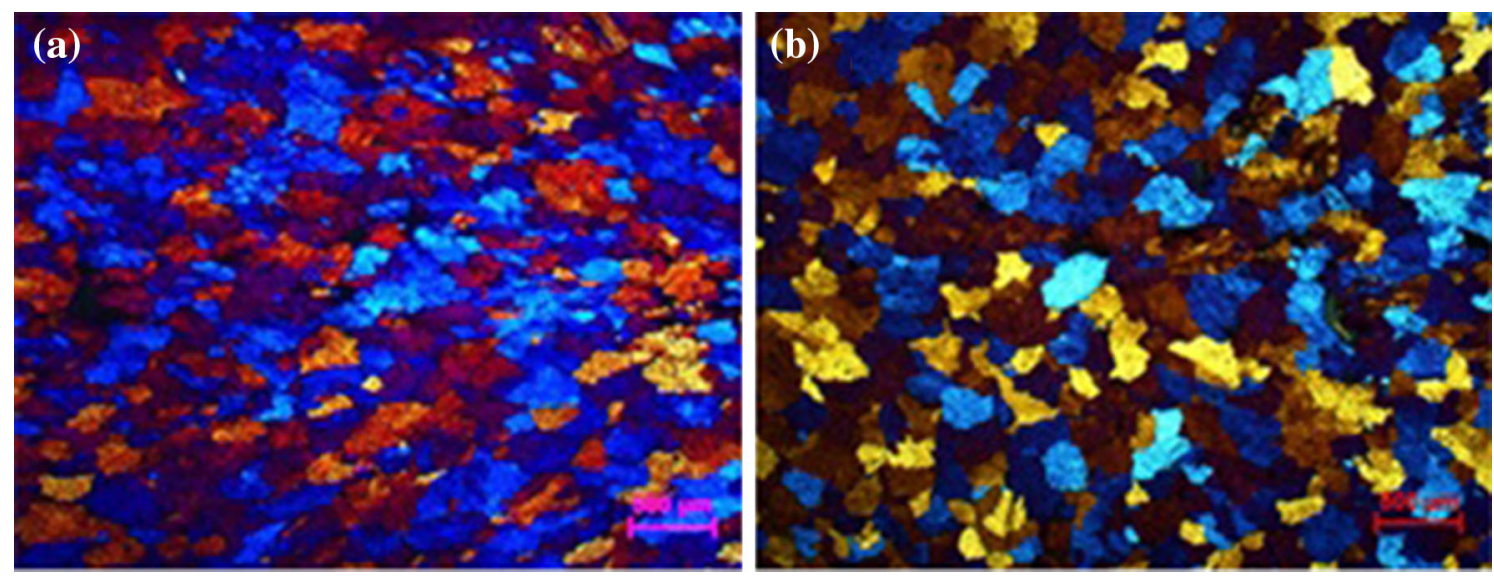

Fig. 2. Optical micrographs of as-cast AA5754 alloy at the center of transverse section of: (a) conventional TRC and (b) MC-TRC. 

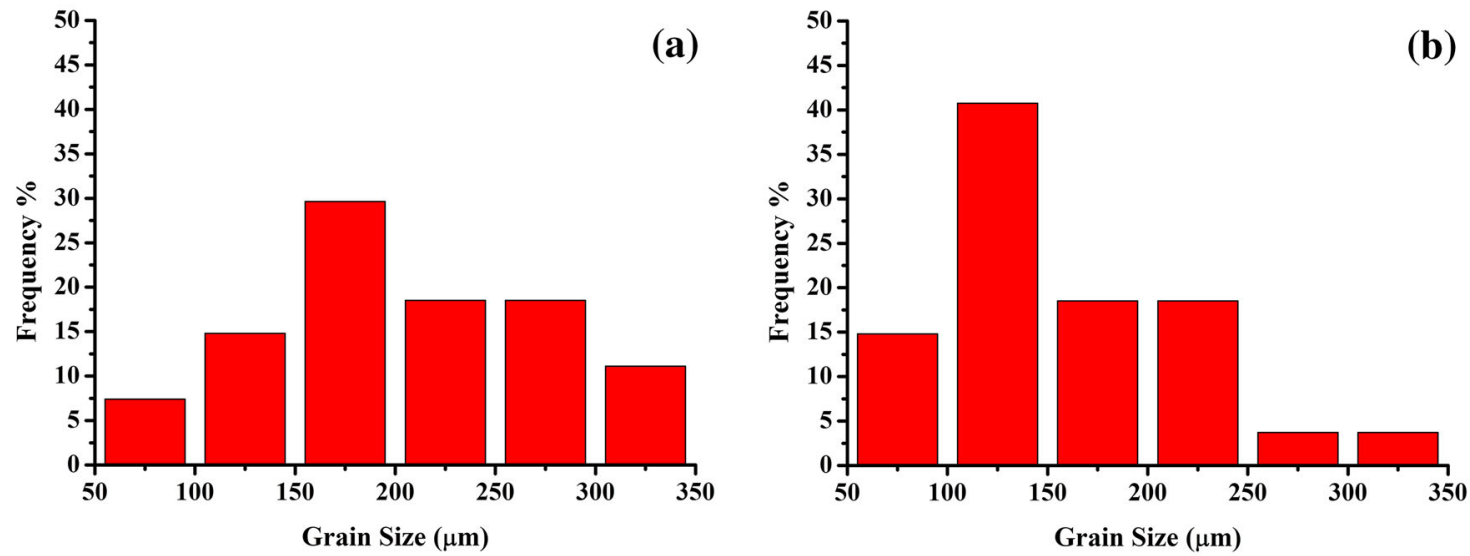

Fig. 3. Grain size distribution of as-cast AA5754 alloy at the transverse section of: (a) conventional TRC and (b) MC-TRC.
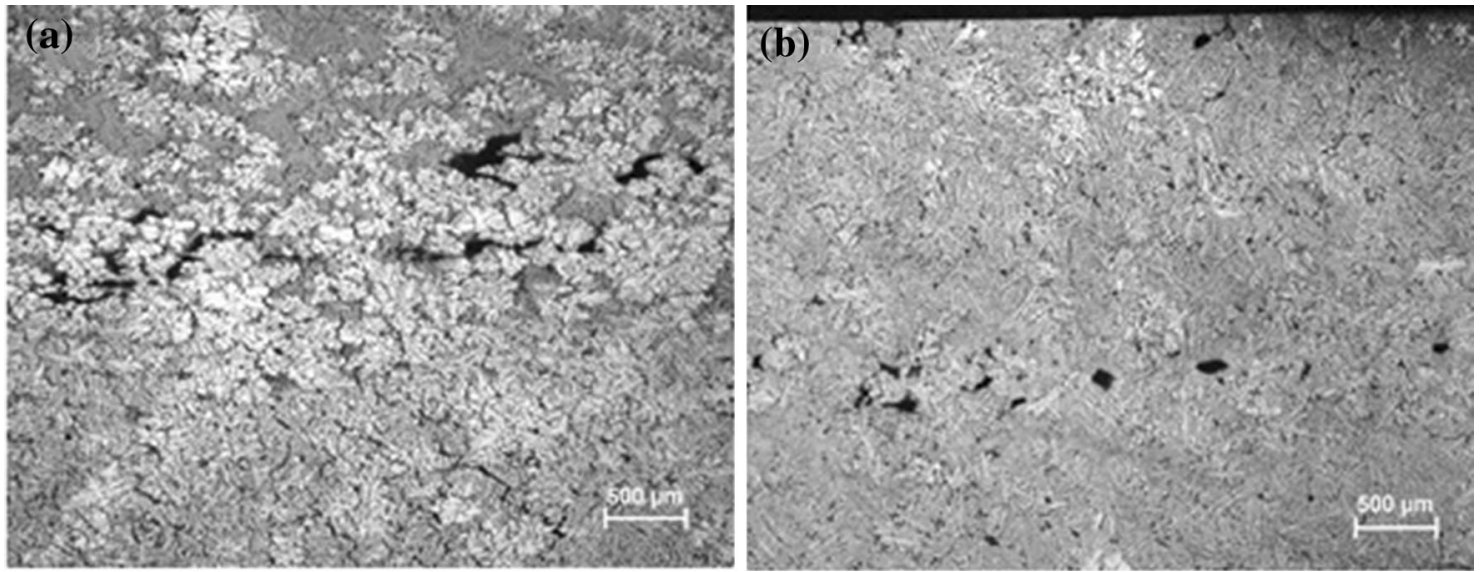

Fig. 4. Optical micrographs of the as-cast AA5754 alloy at the center of the longitudinal section (RD) of (a) conventional TRC and (b) MC-TRC.

grains with hypergeometric distribution, while the micrographs of as-cast MC-TRC showed a relatively finer, equiaxed grain structure with binomial distribution. The average grain size in the transverse section of the MC-TRC strip was $95 \pm 20 \mu \mathrm{m}$, compared with $205 \pm 45 \mu \mathrm{m}$ for the conventional TRC strip. Figure $4 \mathrm{a}$ shows a nonhomogenous matrix structure with continuous centerline segregation for the conventional TRC. Figure $4 \mathrm{~b}$ shows a homogenous matrix structure with discrete centerline channels for the MC-TRC strip.

The observed centerline segregation is attributed to diffusion of solute elements present in the melt, such as silicon, iron, magnesium, manganese, and copper. These elements diffuse from the growing solid-liquid interfaces of the growing columnar grains near the roll surfaces to the center. Also, the enriched melt at the center is pushed back from the cold mushy zone to the hot zone in the sump by the action of the force applied by the rolls. ${ }^{13}$

The reason for the formation of fine equiaxed grains for the high-shear melt-conditioned sample is due to the melt quality. The intensive melt conditioning of the liquid metal disperses naturally existing oxide particles and creates potent nucleating substrates. ${ }^{14}$ These potent substrates nucleate $\alpha-\mathrm{Al}$ and enhance the growth of fine equiaxed grains in a uniform environment. ${ }^{15}$ In practice, the formed oxides are in the form of films and discrete oxide particles, as the melt surface is readily entrained into the casting. ${ }^{16}$ These oxides of different forms break and disperse uniformly throughout the liquid under the physical action of the intensive melt shearing. Under normal casting conditions, the oxide formed in $\mathrm{Al}-\mathrm{Mg}$ alloys is $\mathrm{MgAl}_{2} \mathrm{O}_{4}$, showing lattice misfit with $\alpha$-Al of about $1.4 \%{ }^{17}$ If there is not enough potent substrate, $\mathrm{MgAl}_{2} \mathrm{O}_{4}$ particles can nucleate the primary $\alpha$-Al phase and enhance the casting process. ${ }^{18}$ This led to the formation of the fine equiaxed grain structure and elimination of the solute segregation towards the center of the strip in the MC-TRC process. ${ }^{11}$

\section{Thermomechanical Treatment}

Figure 5 shows micrographs of homogenized strips of the conventional and melt-conditioned TRC strips at the center of the transverse section. The homogenized MC-TRC strip after 

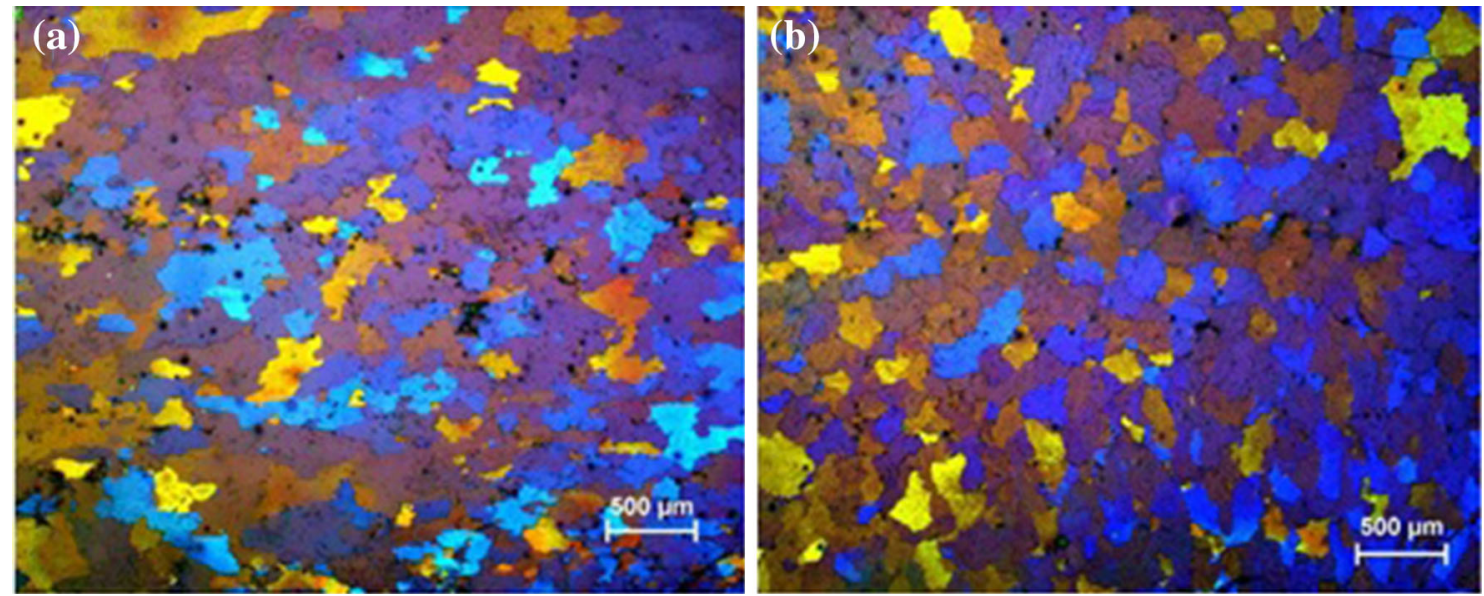

Fig. 5. Optical micrographs of homogenized AA5754 strips after treatment at $520^{\circ} \mathrm{C}$ for $8 \mathrm{~h}$ (TD): (a) conventional TRC and (b) MC-TRC.
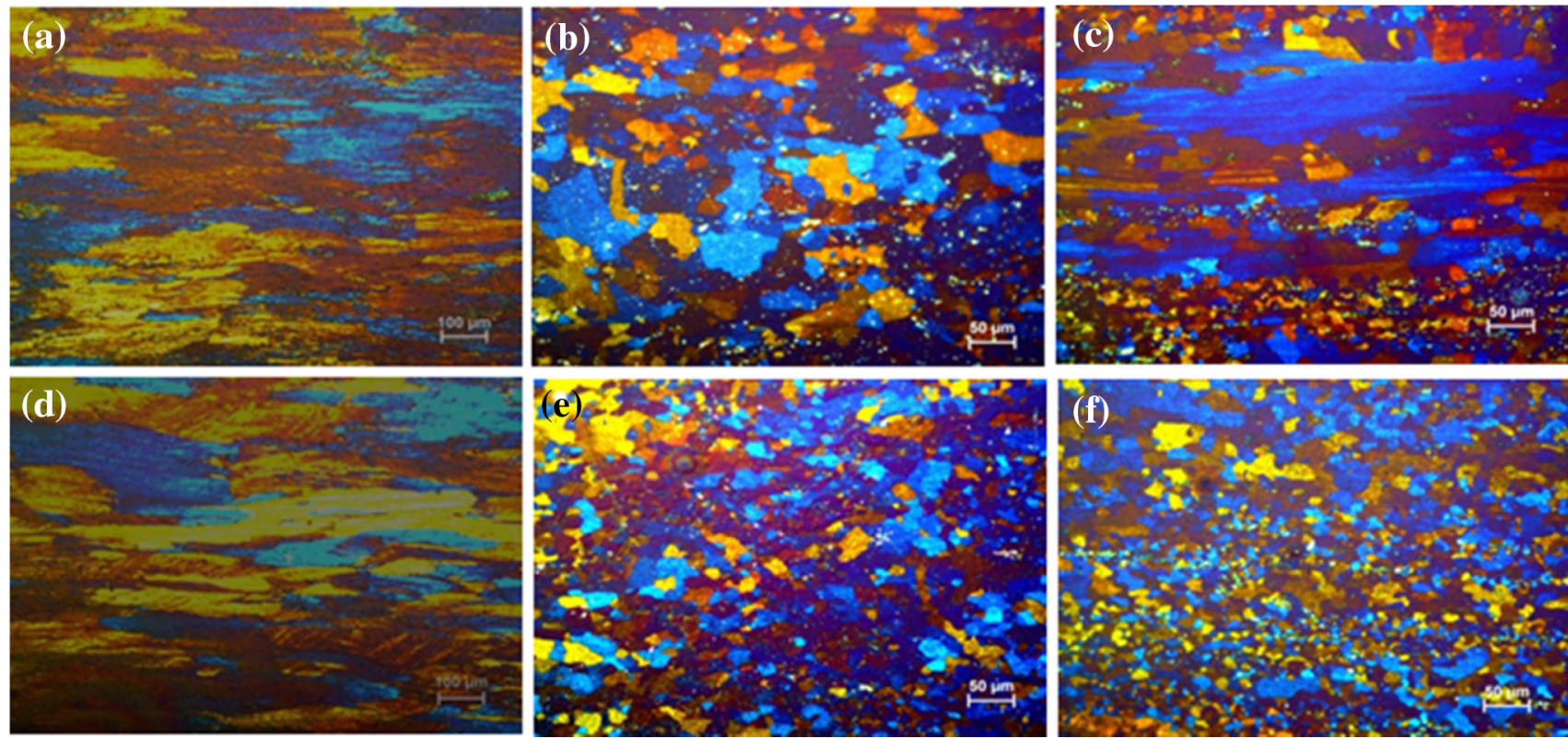

Fig. 6. Optical micrographs of AA5754 strips after (a, d) cold rolling of as-cast TRC and MC-TRC strip (RD), (b, e) annealing at $430^{\circ} \mathrm{C}$ for 30 min of cold-rolled TRC and MC-TRC strip (TD), and (c, f) annealing at $430^{\circ} \mathrm{C}$ for $30 \mathrm{~min}$ of cold-rolled TRC and MC-TRC strip (RD).

treatment at $520^{\circ} \mathrm{C}$ for $8 \mathrm{~h}$ still showed refined equiaxed grains, while the conventional TRC retained the large dendritic grains. The average grain size in the transverse section of the MC-TRC strip was $155 \pm 35 \mu \mathrm{m}$, compared with $350 \pm 65 \mu \mathrm{m}$ for the conventional TRC strip.

Figure 6 shows micrographs of the deformed and heat-treated conventional and melt-conditioned twin-roll cast strips. The deformed MC-TRC strip exhibited a very clear deformation with aspect ratio of 8.22, compared with 3.3 for the TRC strip in the longitudinal section, as shown in Fig. 6a and d. After annealing at $430^{\circ} \mathrm{C}$ for $30 \mathrm{~min}$, the MC-TRC strip in the TD and RD directions showed almost full grain recrystallization compared with the conventional TRC strip, as shown in Fig. 6b, c, e and f, respectively. The longitudinal section of the TRC strip showed partial recrystallization with abnormal grain growth after thermomechanical treatment.

Figure 7 illustrates the grain size distribution found for conventional TRC and MC-TRC castings after thermomechanical treatment, clearly revealing that high-shear melt conditioning could improve the melt quality by achieving a uniform distribution of the nucleation substrate, finally creating refined grains with good size distribution. In the transverse section, the average grain size of the thermomechanically treated MC-TRC strip was $19 \pm 3 \mu \mathrm{m}$, compared with $32 \pm 7 \mu \mathrm{m}$ for the conventional TRC strip.

\section{Mechanical Properties}

Figure 8 shows the tensile properties of the conventional TRC and MC-TRC strips of AA5754 alloy with and without thermomechanical 

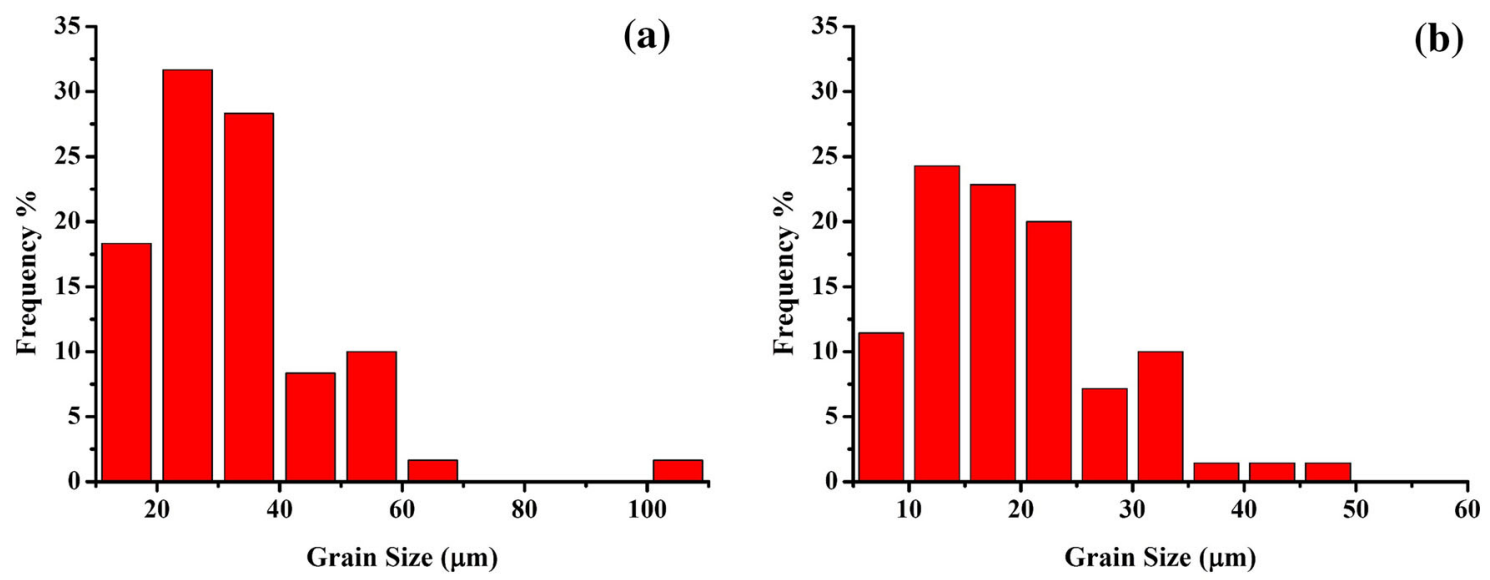

Fig. 7. Grain size distribution of thermomechanically treated (a) TRC and (b) MC-TRC.

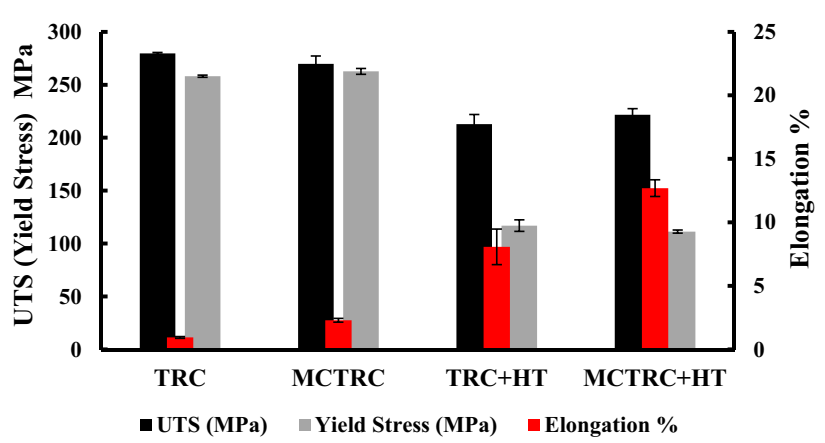

Fig. 8. Effect of intensive melt conditioning and thermomechanical treatment on mechanical properties of AA5754 alloy strip.

treatment. The results show a significant increase in elongation with MC-TRC. The elongation of the MC-TRC sample was $2.3 \%$, compared with $0.95 \%$ for conventional TRC. After homogenization, cold rolling, and annealing, the elongation increased greatly to $12.7 \%$ for the MC-TRC sample compared with $8.08 \%$ for TRC. The ultimate tensile strength for MC-TRC and TRC with thermomechanical treatment was $221.72 \mathrm{MPa}$ and $212.90 \mathrm{MPa}$, respectively. The yield strength for MC-TRC and TRC with thermomechanical treatment was $111.36 \mathrm{MPa}$ and $117.0 \mathrm{MPa}$, respectively. This means that MCTRC with thermomechanical treatment exhibited $57.2 \%$ higher elongation with $4.1 \%$ higher ultimate tensile strength compared with the TRC strip after applying thermomechanical treatment. Generally, increasing the strength occurs at the expense of ductility properties. However, with a fine, homogenous grain size distribution and the elimination of centerline segregation, both the strength and ductility can be increased.

As discussed above, intensive melt conditioning improves the microstructure by refining the grains and eliminates centerline segregation, finally improving the mechanical properties. Demiray et al. ${ }^{19}$ found that the tensile strength and yield strength of AA5754 alloy were almost constant when annealed at between $400^{\circ} \mathrm{C}$ and $520^{\circ} \mathrm{C}$ for $3 \mathrm{~h}$, while the elongation increased from $17.6 \%$ to $25.5 \%$. Their findings are in agreement with our results.

\section{CONCLUSION}

1. The present study showed that, by using highshear melt conditioning, the solidification during twin-roll casting can be controlled. Applying high shear prior to twin-roll casting of recycled AA5754 alloy can improve the melt quality and produce a sheet with good mechanical properties.

2. Recycled AA5754 strips of MC-TRC showed fine equiaxed grains and uniform structure with the elimination of centerline segregation and almost full recrystallization after thermomechanical treatment. MC-TRC with thermomechanical treatment can increase the impurities tolerance of recycled aluminum alloys obtained using postconsumer scrap in the melt formulation.

3. It is important to note that samples produced using MC-TRC with thermomechanical treatment exhibited better tensile properties than those obtained by conventional TRC. The elongation and ultimate tensile strength of MC-TRC were both higher than those of conventional TRC.

\section{ACKNOWLEDGEMENTS}

The support from Primetals Technologies, UK, is acknowledged with gratitude. Funding was provided by Innovate UK (Grant No. R33599).

\section{OPEN ACCESS}

This article is distributed under the terms of the Creative Commons Attribution 4.0 International License (http://creativecommons.org/licenses/by/4.0/), which permits unrestricted use, distribution, and reproduction in any medium, provided you give 
appropriate credit to the original author(s) and the source, provide a link to the Creative Commons license, and indicate if changes were made.

\section{REFERENCES}

1. J.D. Hunt, M. Yun, S. Lockyer, and M.J. Heywood, in Light Metals, ed. R. Huglen (1997), pp. 341-354.

2. J.A. Taylor, Procedia Mater. Sci. 1, 19 (2012).

3. Z. Lifeng, G. Jianwei, N. Lucas, and G. David, Miner. Process. Extr. Metall. Rev. 33, 99 (2012).

4. Z. Wei-wen, L. Bo, L. Zhi, Z. Yu-Liang, and L. Yuan-yuan, J. Mater. Res. 30, 2474 (2015).

5. H. Toshio, I. Masaaki, W. Hisaki, S. Kenta, and K. Shinji, Mater. Trans. 46, 2596 (2005).

6. C.A. Santos, J.A. Spim Jr., and A. Garcia, J. Mater. Proc. Technol. 102, 33 (2000).

7. J.B. Patel, H.T. Li, M.X. Xia, S. Jones, S. Kumar, K. O'Reilly, and Z. Fan, Mater. Sci. Forum 794, 149 (2014).

8. N.S. Barekar, S. Das, Z. Fan, R. Cinderey, and N. Champion, Mater. Sci. Forum 790, 285 (2014).
9. Z. Fan, Y. Wang, M. Xia, and S. Arumuganathar, Acta Mater. 57, 4891 (2009).

10. S. Kumar, N.H. Babu, G.M. Scamans, and Z. Fan, Mater. Sci. Technol. 27, 1833 (2011).

11. N.S. Barekar, S. Das, X. Yang, Y. Huang, O. El Fakir, A.G. Bhagurkar, L. Zhou, and Z. Fan, Mater. Sci. Eng. A 650, 365 (2016).

12. ASTM Designation: B 557M-02a, Standard Test Methods of Tension Testing Wrought and Cast Aluminum- and Magnesium-Alloy Products [Metric] (2003).

13. S. Kumar, N.H. Babu, G. Scamans, and Z. Fan, in Proceedings of the 12th International Conference on Aluminium Alloys, Yokohama, Japan, September 5-9 (2010).

14. H.T. Li, Y. Wang, and Z. Fan, Acta Mater. 60, 1528 (2012).

15. J.B. Patel, X. Yang, C.L. Mendis, and Z. Fan, JOM 69, 1071 (2017).

16. J. Campbell, Metall. Mater. Trans. B 37, 857 (2006).

17. H.T. Li, Y. Wang, and Z. Fan, Acta Mater. 60, 1528 (2012).

18. M.X. Zhang, P.M. Kelly, M. Qian, and J.A. Taylor, Acta Mater. 53, 3261 (2005).

19. Y. Demiray, Z.B. Kavaklioglu, and O. Yucel, in Proceedings of the 4th International Congress APMAS2014, Fethiye, Turkey, April 24-27 (2014). 